\title{
Catalytic Transformation of Fructose and Sucrose to HMF with Proline-Derived Ionic Liquids under Mild Conditions
}

\author{
Hu Li and Song Yang \\ State-Local Joint Laboratory for Comprehensive Utilization of Biomass, State Key Laboratory Breeding Base of Green Pesticide \\ and Agricultural Bioengineering (Ministry of Education), Center for Research and Development of Fine Chemicals, \\ Guizhou University, Guiyang 550025, China \\ Correspondence should be addressed to Hu Li; lhpesticide@163.com and Song Yang; jhzx.m8m@gmail.com
}

Received 19 January 2014; Revised 9 March 2014; Accepted 10 March 2014; Published 27 March 2014

Academic Editor: Dmitry Murzin

Copyright (C) 2014 H. Li and S. Yang. This is an open access article distributed under the Creative Commons Attribution License, which permits unrestricted use, distribution, and reproduction in any medium, provided the original work is properly cited.

\begin{abstract}
$L$-Proline derived ionic liquids (ILs) used as both solvent and catalyst were efficient for transformation of fructose and sucrose to 5hydroxymethylfurfural (HMF) in the presence of water. Response surface methodology (RSM) was employed to optimize fructose dehydration process, and a maximum HMF yield of $73.6 \%$ could be obtained at $90^{\circ} \mathrm{C}$ after 50 min. The recycling of the IL exhibited an almost constant activity during five successive trials, and a possible reaction mechanism for the dehydration of fructose to HMF was proposed.
\end{abstract}

\section{Introduction}

Biomass derivatives and related raw materials are the most abundant renewable resources available which have great potential as biofuels and chemical building blocks for a diverse range of applications [1-4]. Over the past decades, various acid and/or base catalysts have been employed to transform carbohydrates into different kinds of furans, providing a feasible way for supplying sustainable energy and chemicals [5-7]. Amongst them, 5-hydroxymethylfurfural (HMF), serving as an important precursor molecule in the production of fine chemicals, plastics, pharmaceuticals, and liquid fuels $[8,9]$, can be synthesized from biomass-derived carbohydrates such as fructose and sucrose. In this catalytic dehydration process, various acid catalysts including mineral acids $[10,11]$, metal ions [12-14], ion exchange resins [1517], $-\mathrm{SO}_{3} \mathrm{H}$ functionalized catalysts $[18,19]$, and many other functional materials [20-24] have been used, which may find applications in HMF production.

During the past decade, ionic liquids (ILs) considered to be salts with a melting point below $100^{\circ} \mathrm{C}$ have been widely utilized as reaction media or catalysts for the dehydration of carbohydrates into HMF. Using 1-butyl-3-methylimidazol3-ium hexafluorophosphate $\left([\mathrm{Bmim}] \mathrm{PF}_{6}\right)$ or 1-butyl-3methylimidazolium tetrafluoroborate $\left([\mathrm{Bmim}] \mathrm{BF}_{4}\right)$ as reaction medium, fructose could be selectively transformed into $\mathrm{HMF}$ with up to 50\% yield in the presence of Amberlyst 15 at $80^{\circ} \mathrm{C}$ for $3 \mathrm{~h}$ [25]. Similarly, Li et al. [26] found that acidic ion-exchange resins in 1-butyl-3-methylimidazolium chloride $([\mathrm{Bmim}] \mathrm{Cl})$ could effectively promote dehydration of fructose to HMF, and a 93.0\% yield of HMF was obtained at $75^{\circ} \mathrm{C}$ for $20 \mathrm{~min}$. Moreover, metal chlorides combined with ILs were also demonstrated to be highly efficient for carbohydrates. For instance, chromium(III)/(II) chloride mediated catalytic systems for dehydration of carbohydrates to HMF always showed excellent reactivity [27-29], giving up to $99 \% \mathrm{HMF}$ yield from fructose at $100^{\circ} \mathrm{C}$ within $6 \mathrm{~h}$ [27]. Most recently, Zhou et al. [30] reported that synthesis of HMF from carbohydrates catalyzed by $\mathrm{ScCl}_{3}$ in $[\mathrm{Bmim}] \mathrm{Cl}$ under microwave irradiation at $400 \mathrm{~W}$ could be achieved with a high yield of $73.4 \%$ in $2 \mathrm{~min}$. With the presence of $\mathrm{HfCl}_{4}$ and $\mathrm{NbCl}_{5}$, $\mathrm{HMF}$ yield of up to $77.5 \%$ and $79 \%$ could be obtained from fructose after $30 \mathrm{~min}$ at $100^{\circ} \mathrm{C}$ and $80^{\circ} \mathrm{C}$, respectively [31,32].

Apart from acting as reaction media, acidic/basic ILs could be directly employed as catalysts for the production of HMF from carbohydrates. In an aqueous acetonitrile biphasic system, a HMF yield of up to $88.7 \%$ could be achieved in the presence of a Lewis acidic IL, 
that is, 1-methyl-3-(butyl-4-chlorosulfonyl)-imidazolium chlorosulfate $\left([\mathrm{MBCIm}] \mathrm{SO}_{3} \mathrm{Cl}\right)$, at $80^{\circ} \mathrm{C}$ after $4 \mathrm{~h}$ [33]. Likewise, 3-allyl-1-(4-sulfurylchloride butyl)-imidazolium trifluoromethanesulfonate ([ASCBI][Tf]) was capable of effectively catalyzing the dehydration of D-fructose to HMF with around $70 \%$ yield at $100 \%$ fructose conversion in DMSO (dimethyl sulfoxide) within 4 min under microwave irradiation of $200 \mathrm{~W}$ [34]. On the other hand, Brønsted acidic ILs [35-37] and even alkaline ILs [38] could promote the dehydration process, which indicated the high catalytic performance of ILs in the synthesis of HMF from carbohydrates.

Notably, Moreau et al. [39] found that 1-H-3-methyl imidazolium chloride $\left(\mathrm{HMIM}^{+} \mathrm{Cl}^{-}\right)$could be used as both solvent and catalyst for the dehydration of fructose and sucrose to produce HMF in relatively high yield and selectivity. This catalytic system largely facilitated the separation of HMF from the reaction solution and showed great potential in industrial applications. Similarly, a dicationic room temperature IL $\left[\right.$ TetraEG $\left.(\mathrm{mim})_{2}\right][\mathrm{OMs}]_{2}$ (tetra ethylene glycol-bis (3-methylimidazolium) dimesylate) afforded $92.3 \%$ of HMF yield from fructose in $40 \mathrm{~min}$ at $120^{\circ} \mathrm{C}$ [40]. By using 3-(2-chloroethyl)-1-methylimidazolim chloride $\left(\left[\mathrm{ClC}_{2} \mathrm{mim}\right] \mathrm{Cl}\right)$ as both catalyst and solvent in the presence of water, $76 \%$ HMF yield could be obtained from fructose at $100^{\circ} \mathrm{C}$ in $40 \mathrm{~min}$ [41]. However, imidazolium-based ILs are always expensive and have a certain toxicity [42]. With the increasing concern about economic development and environmental protection, ILs synthesized from biorenewable materials may offer a competitive route to the traditional imidazolium-based ionic liquids $[37,43]$.

Starting from amino acids, Tao et al. [44] prepared a series of amino acid-based ILs that are thermally stable up to $150-200^{\circ} \mathrm{C}$ via a simple protonation reaction carried out by mixing the correct molar ratio of amino acid with relevant strong acid in water. In particular, $L$-proline possessing nature endorsed chiral center was reported to exhibit excellent enantioselectivities in several types of asymmetric reactions $[45,46]$, and its ionic liquid counterparts could well promote organic synthesis $[47,48]$. In the present study, proline chlorate (ProCl) and proline bisulfate $\left(\mathrm{ProHSO}_{4}\right)$ were synthesized and further employed for the dehydration of fructose and sucrose to HMF in the presence of water. Response surface methodology (RSM) was utilized to optimize fructose dehydration process, and a possible reaction mechanism for the dehydration of fructose to HMF was proposed.

\section{Experimental}

2.1. Materials. L-Proline, boric acid, glycerol, fructose, sucrose, and HMF of analytical grade were purchased from Shanghai Aladdin Industrial Inc.; 1-Methylimidazole (AR, 99\%) and 1,3-propanesultone (>99\%) were purchased from Sinopharm Chemical Reagent Co., Ltd. All the other chemicals were of analytical grade and used as received, unless otherwise noted.
2.2. Preparation of Ionic Liquids. Proline chlorate (ProCl) and proline bisulfate $\left(\mathrm{ProHSO}_{4}\right)$ were synthesized according to the reported methods $[49,50]$ with slight modifications. Equal moles of hydrochloride or sulfuric acid $(6 \mathrm{~mol} / \mathrm{L})$ were added dropwise to the solution of $L$-proline $(2.88 \mathrm{~g}, 25 \mathrm{mmol}$ ) dissolved in $15 \mathrm{~mL}$ of water. The reaction mixture was then heated to $60^{\circ} \mathrm{C}$ and kept stirring for $24 \mathrm{~h}$. Upon completion, the mixture was concentrated and evaporated under vacuum to give the target protic ionic liquid in high yield (around 95\%).

ProCl ${ }^{1} \mathrm{H}$ NMR (DMSO, $\left.500 \mathrm{MHz}\right): \delta(\mathrm{ppm})=4.19(\mathrm{~m}$, $1 \mathrm{H}), 3.15(\mathrm{~m}, 2 \mathrm{H}), 2.21(\mathrm{~m}, 1 \mathrm{H}), 1.85(\mathrm{~m}, 3 \mathrm{H}) ;{ }^{13} \mathrm{C}$ NMR $(\mathrm{DMSO}, 125 \mathrm{MHz}): \delta(\mathrm{ppm})=170.69,59.05,45.57,28.49$, 23.62; IR (KBr): $\nu\left(\mathrm{cm}^{-1}\right)=2940,2700-2500,1738,1573,1384$, 1213, 821, 658.

ProHSO $_{4}{ }^{1} \mathrm{H}$ NMR (DMSO, $\left.500 \mathrm{MHz}\right): \delta(\mathrm{ppm})=4.28$ (m, 1H), $3.24(\mathrm{~m}, 2 \mathrm{H}), 2.30(\mathrm{~m}, 1 \mathrm{H}), 1.94(\mathrm{~m}, 3 \mathrm{H}) ;{ }^{13} \mathrm{C} \mathrm{NMR}$ (DMSO, $125 \mathrm{MHz}): \delta(\mathrm{ppm})=169.89,58.84,45.47,28.19$, 23.22; IR $(\mathrm{KBr}): \nu\left(\mathrm{cm}^{-1}\right)=3168,1741,1587,1423,1341,1138$, $1062,876,658,572$.

For comparison, 1-methyl-3-(3-sulfopropyl)-imidazolium chloride $\left(\left[\mathrm{C}_{3} \mathrm{SO}_{3} \mathrm{Hmim}\right][\mathrm{Cl}]\right)$, 1-methyl-3-(3-sulfopropyl)imidazolium hydrogen sulfate $\left(\left[\mathrm{C}_{3} \mathrm{SO}_{3} \mathrm{Hmim}\right]\left[\mathrm{HSO}_{4}\right]\right)$, and 1-propyl-3-methylimidazolium chloride $\left(\left[\mathrm{C}_{3} \mathrm{mim}\right][\mathrm{Cl}]\right)$, as well as bis(glycerol)boric acid $\left(\mathrm{H}\left[\mathrm{Gly}_{2} \mathrm{~B}\right]\right)$, were synthesized according to the procedures depicted by Li et al. [19] and Safaei et al. [51].

2.3. Catalytic Transformation of Carbohydrates into HMF. As a general procedure, a $15 \mathrm{~mL}$ of sealed tube (Ace, pressure limit: 20 bar) was charged with $1.0 \mathrm{~g}$ of ionic liquid, $5 \mathrm{wt} \%$ water, and fructose or sucrose $(100 \mathrm{mg}, 0.56 \mathrm{mmol})$ by oil heating at a fixed temperature stirring for a specified time. Upon completion, the tube was removed from the oil bath and cooled to room temperature. Deionized water was then added to quantify the reaction mixture in a volumetric flask before the sample was taken for analysis by HPLC.

2.4. Product Analysis. High-performance liquid chromatography (HPLC; Agilent 1100, USA) fitted with a Lichrospher C18 column, an ultraviolet detector at $284 \mathrm{~nm}$, a column oven temperature set at $25^{\circ} \mathrm{C}$, and a mobile phase of methanol/water $(35 / 65, \mathrm{v} / \mathrm{v})$ at a flow rate of $0.8 \mathrm{~mL} / \mathrm{min}$ were used to determine the yield of HMF. The concentration of HMF was calculated based on the standard curve obtained with the standard substances, and HMF yield was further calculated from the equation: HMF yield $(\%)=($ moles of $\mathrm{HMF}) /($ moles of hexose added $) \times 100$.

\section{Results and Discussion}

3.1. Catalytic Dehydration of Fructose into HMF with Different ILs. Ionic liquids (ILs) are often highly viscous and sensitive to moisture. In this study, a certain amount of water was added into the reaction system with the aim of reducing the viscosity of ILs and discussing the effect of water contents on catalytic performance. Initially, a water content of $5 \mathrm{wt} \%$ previously reported to promote HMF formation in carbohydrate 


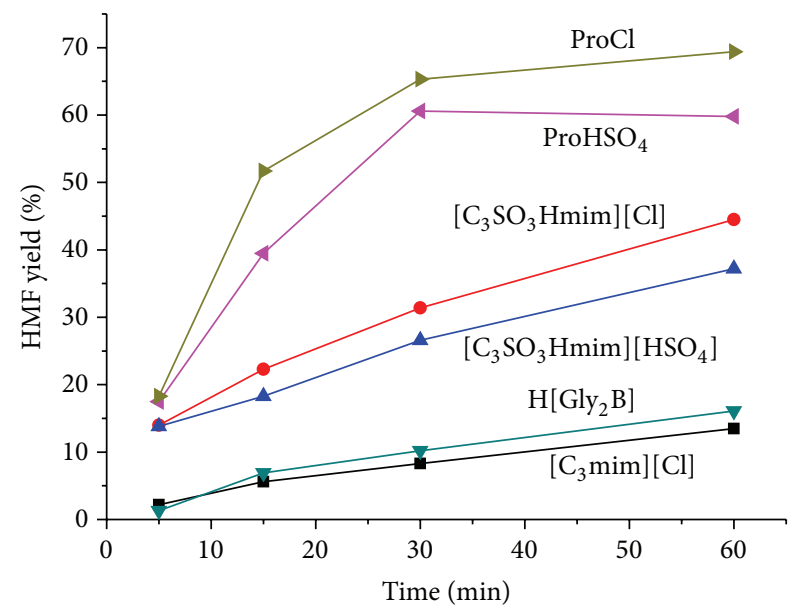

FIGURE 1: Catalytic dehydration of fructose to HMF over various ILs with $5 \mathrm{wt} \%$ water at $90^{\circ} \mathrm{C}$ for different reaction times.

dehydration [52] was employed to investigate the reactivity of various ILs. As shown in Figure 1, protic ionic liquids (ProCl and $\mathrm{ProHSO}_{4}$ ) exhibited better catalytic activity (up to $\sim 70 \%$ HMF yield) than others. However, boron core based protic ionic liquid $\left(\mathrm{H}\left[\mathrm{Gly}_{2} \mathrm{~B}\right]\right)$ similar to $\left[\mathrm{C}_{3} \mathrm{mim}\right][\mathrm{Cl}]$ produced relatively low HMF yields despite boric acid could be used as a promoter for dehydration of carbohydrates in ionic liquids [53]. Although, $-\mathrm{SO}_{3} \mathrm{H}$ functionalized imidazolium-based ILs $\left(\left[\mathrm{C}_{3} \mathrm{SO}_{3} \mathrm{Hmim}\right][\mathrm{Cl}]\right.$ and $\left.\left[\mathrm{C}_{3} \mathrm{SO}_{3} \mathrm{Hmim}\right]\left[\mathrm{HSO}_{4}\right]\right)$ were reported to be efficient for fructose-to-HMF conversion in biphasic system at high temperature for a long reaction time [54]; they only displayed moderate HMF yields (30-40\%) under mild reaction conditions (Figure 1). In both cases, the reactivity of chloride anion based ILs was superior to that of ILs containing hydrogen sulfate ion, which indicated the vital role of chloride anion in catalytic dehydration of fructose $[55,56]$. On the other hand, the proline-derived ILs were much more efficient for fructose-to-HMF conversion than other cations based ILs, which implied the enhanced effect of carboxylic groups $(-\mathrm{COOH})$ of proline-derived ILs on adsorption and transformation of the substrate.

\subsection{Effect of Water Content on Catalytic Dehydration of} Fructose to $H M F$. Due to the acceptable catalytic performance, $\mathrm{ProCl}$ and $\mathrm{ProHSO}_{4}$ were further utilized to test the influence of water content on dehydration of fructose to HMF (Figure 2). Up to $10 \mathrm{wt} \%$ of water in the reaction mixture resulted in no detrimental effect on the formation of HMF from fructose, which to some extent showed the synergy of $\mathrm{ProCl}$ and water in the catalytic dehydration of fructose to HMF. However, the HMF yield significantly decreased as water content was above $10 \mathrm{wt} \%$, which might be ascribed to the generation of hydrated chloride ions that are unable to participate in the reaction [57]. In contrast, very negative effect of water content on fructose-to-HMF conversion over $\mathrm{ProHSO}_{4}$ was observed. Instead of HMF, large amounts of levulinic acid (up to $40 \%$ yield) and humins were obtained. It was speculated that free $\mathrm{HSO}_{4}{ }^{-}$with high acid strength as

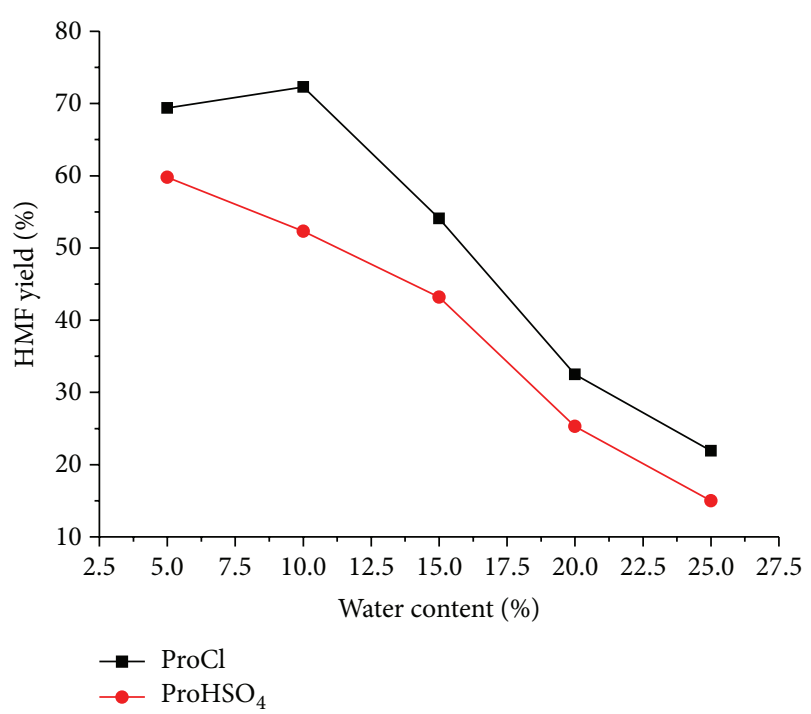

Figure 2: Effect of water content in $\mathrm{ProCl}$ and $\mathrm{ProHSO}_{4}$ on dehydration of fructose to $\mathrm{HMF}$ at $90^{\circ} \mathrm{C}$ for $60 \mathrm{~min}$.

well as water content in $\mathrm{ProHSO}_{4}$ mediated reaction system was responsible for hydrolysis/degradation of HMF.

3.3. Influence of Reaction Time and Temperature on Fructoseto-HMF Conversion. Apart from water content, reaction temperature and time are another two important parameters to determine the yields of HMF. Optimized experiments were thus performed on fructose dehydration at reaction temperature ranging from 70 to $110^{\circ} \mathrm{C}$ for reaction duration in the range of 5-75 min in ProCl with $10 \mathrm{wt} \%$ of water (Figure 3). At a temperature of $70^{\circ} \mathrm{C}, \mathrm{HMF}$ yields kept increasing with the increase of reaction time from $5 \mathrm{~min}$ to $75 \mathrm{~min}$, giving only $36 \%$ yield of HMF even after $75 \mathrm{~min}$. Seemingly, high temperature $\left(110^{\circ} \mathrm{C}\right)$ was beneficial for fructose dehydration to HMF within short time. However, extension of the reaction duration to 75 min just afforded around 20\% HMF yield. In turn, fructose dehydration at $90^{\circ} \mathrm{C}$ could produce a little higher yield of HMF (about 70.0\%) after 40 min though the reaction rate was somewhat slower.

3.4. Optimization of The Reaction Conditions Using Experimental Design. A three-factor two level design [58] was employed with the purpose of optimizing the reaction conditions for the dehydration of fructose to HMF with higher yields. Three factors as reaction temperature $\left(T /{ }^{\circ} \mathrm{C}\right)$, reaction time $(t / \mathrm{min})$, and $\mathrm{ProCl}$ amount $(\mathrm{C} / \mathrm{g})$ were tested for fructose-to-HMF transformation. Figures 4,5 , and 6 show the effects of reaction temperature, reaction time, and $\mathrm{ProCl}$ amount on HMF yield. With the experimental design, a model equation for predicting HMF yield in the fructose dehydration was generated: HMF yield $(\%)=-786.0522+$ $(2.3178 t)+(17.4576 T)+(32.9100 C)-(0.0172 t T)+(0.0600 t C)$ $+(0.1525 T C)-\left(0.0085 t^{2}\right)-\left(0.0936 T^{2}\right)-\left(20.7300 C^{2}\right)$. From the optimization, $90^{\circ} \mathrm{C}, 50 \mathrm{~min}$, and $1.2 \mathrm{~g} \mathrm{ProCl}$ were disclosed to be one of the optimum reaction conditions. Under the reaction condition, the actual HMF yield of $73.6 \%$ 


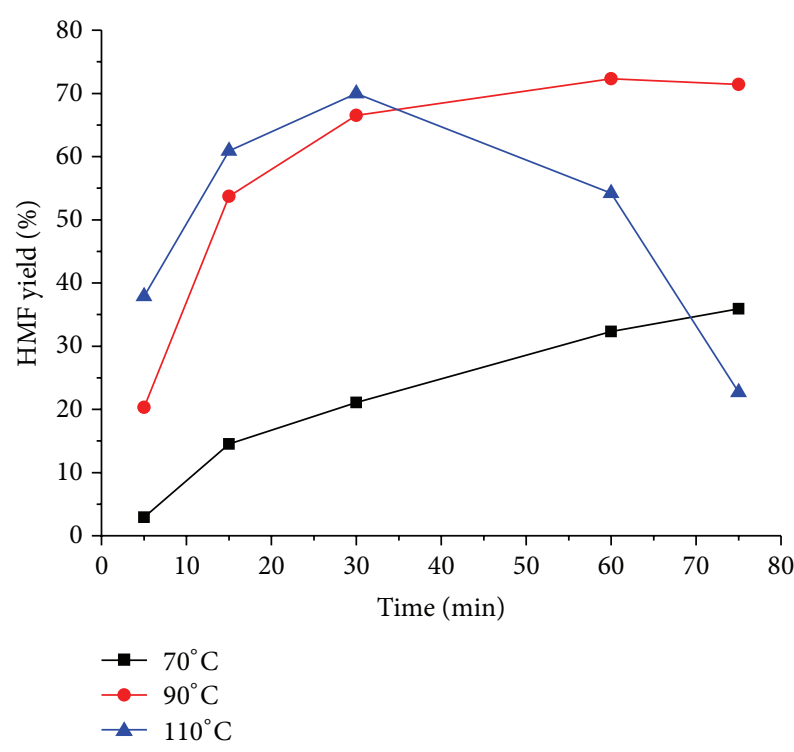

FIGURE 3: Effect of reaction time and temperature on catalytic dehydration of fructose to $\mathrm{HMF}$ in $\mathrm{ProCl}$ with $10 \mathrm{wt} \%$ of water.

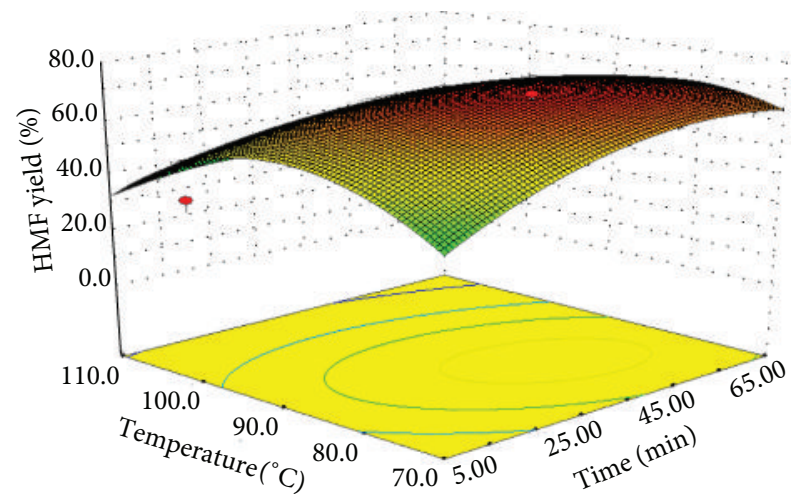

FIGURE 4: Response surface plot of HMF yield against reaction temperature and time.

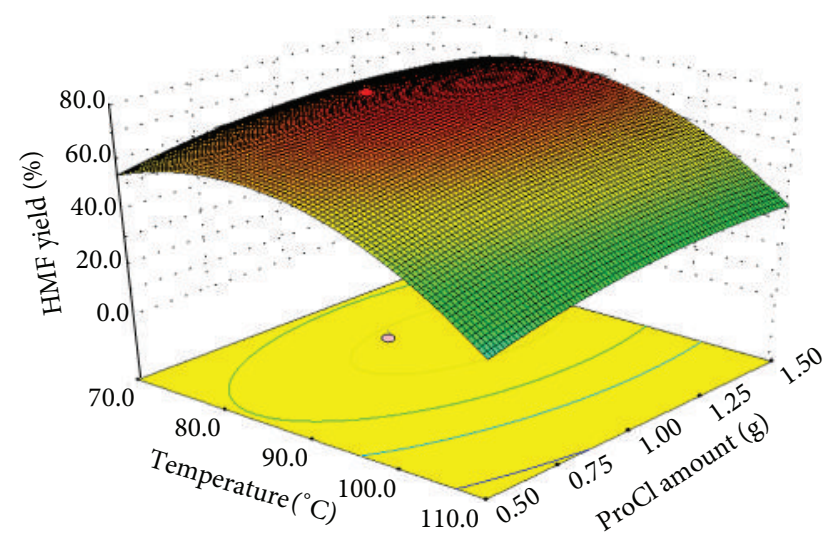

Figure 5: Response surface plot of HMF yield against reaction temperature and $\mathrm{ProCl}$ amount.

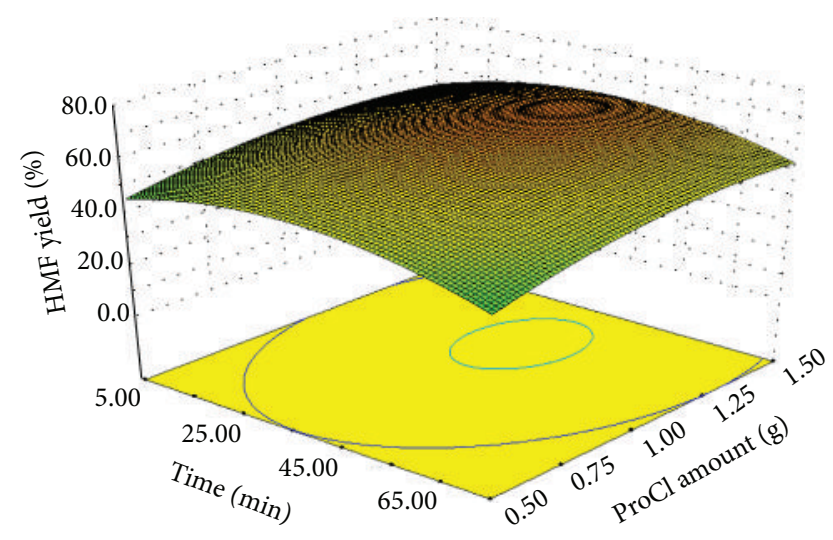

FIGURE 6: Response surface plot of HMF yield against reaction time and ProCl amount.

was achieved in accordance with the predicted yield of $74.1 \%$, which well validated the model.

3.5. Catalytic Dehydration of Sucrose to HMF. Sucrose as a disaccharide consisting of glucose and fructose is widely distributed in the plant kingdom, showing promising prospect in the production of value-added chemicals [59]. However, only $\sim 18 \%$ HMF yield was obtained from sucrose under the reaction condition optimized for fructose dehydration (i.e., $90^{\circ} \mathrm{C}, 50 \mathrm{~min}, 1.2 \mathrm{~g}$ ProCl, and $10 \mathrm{wt} \%$ of water), as shown in Figure 7. The HMF yield increased as the reaction proceeded for a long reaction time, and around 35\% and $40 \%$ yield of HMF could be achieved within $150 \mathrm{~min}$ and $180 \mathrm{~min}$, respectively, which clearly demonstrated the relatively higher stability of sucrose as compared with fructose. However, the catalytic performance in terms of HMF yield was decreased as the reaction time was further increased to 210 or $240 \mathrm{~min}$, implying that glucose with equal amount of molar weight to fructose in sucrose could not be effectively dehydrated by the protic IL whereas the degradation of HMF seriously happened [39]. In this regard, further increasing water content as well as reaction temperature would only facilitate the side reactions to degrade HMF.

3.6. HMF Separation and IL Recycling. The separation of $\mathrm{HMF}$ and the recycling of ProCl were studied in fructose dehydration, and all the experiments (five cycles) were carried out in $1.2 \mathrm{~g}$ ProCl with $10 \mathrm{wt} \%$ of water at $90^{\circ} \mathrm{C}$ for $50 \mathrm{~min}$. After the reaction, HMF was extracted with diethyl ether in a stepwise manner [39], and the IL recovered by removal of residual water was directly used for the next cycle after adding a certain amount of water. It was found that the amount of the recovered IL was slightly decreased from $1.20 \mathrm{~g}$ to $1.14 \mathrm{~g}$ after the first run. As illustrated in Figure 8, the recycling of ProCl exhibited almost constant reactivity with respect to the percent yield of HMF (around 70\%) within five runs.

3.7. Proposed Mechanism for Catalytic Dehydration of Fructose to $\mathrm{HMF}$ with ProCl. Compared with the above discussed ILs, the relatively better activity of $L$-proline based protic ILs 


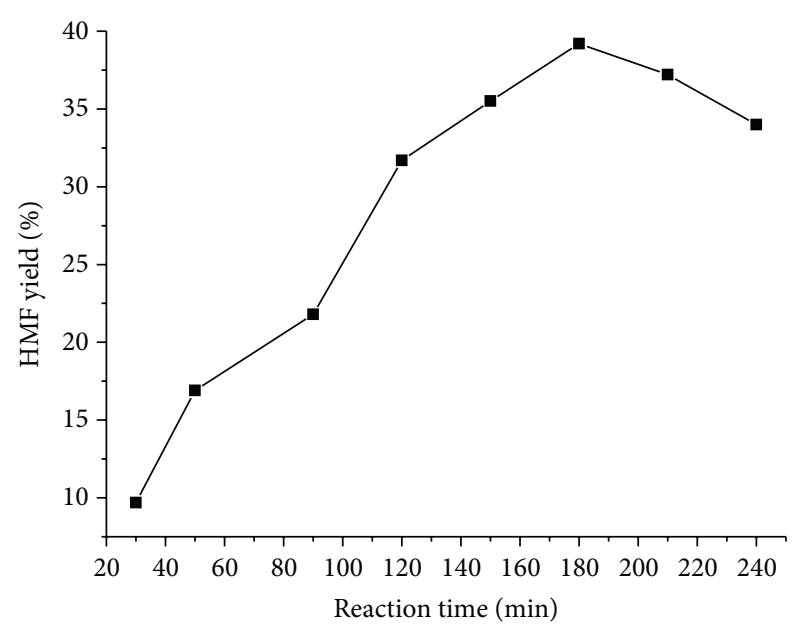

Figure 7: Catalytic dehydration of sucrose to HMF in ProCl with $10 \mathrm{wt} \%$ water at $90^{\circ} \mathrm{C}$.

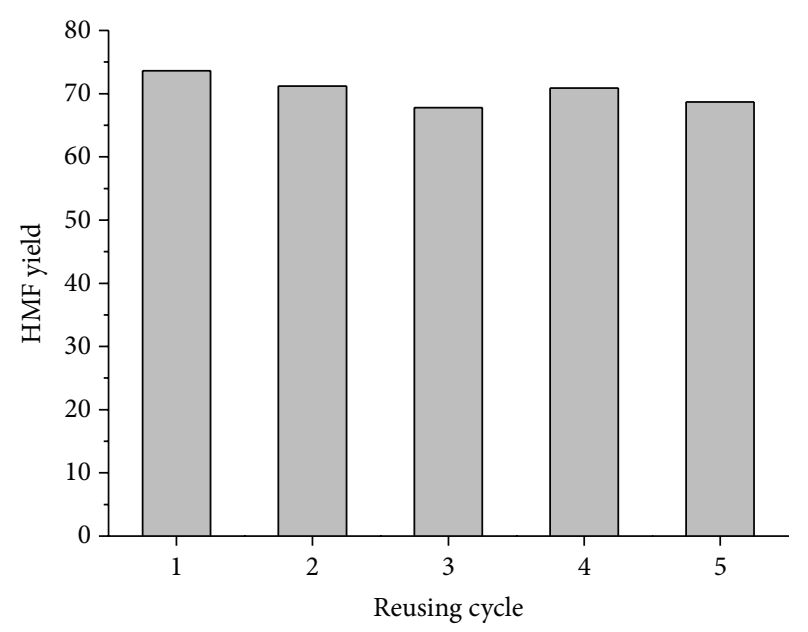

FIGURE 8: The recycling of ProCl for dehydration of fructose to HMF. Reaction conditions: $\mathrm{ProCl}(1.2 \mathrm{~g})$, water $(10 \mathrm{wt} \%)$ and fructose $(100 \mathrm{mg})$ at $90^{\circ} \mathrm{C}$ for $50 \mathrm{~min}$.

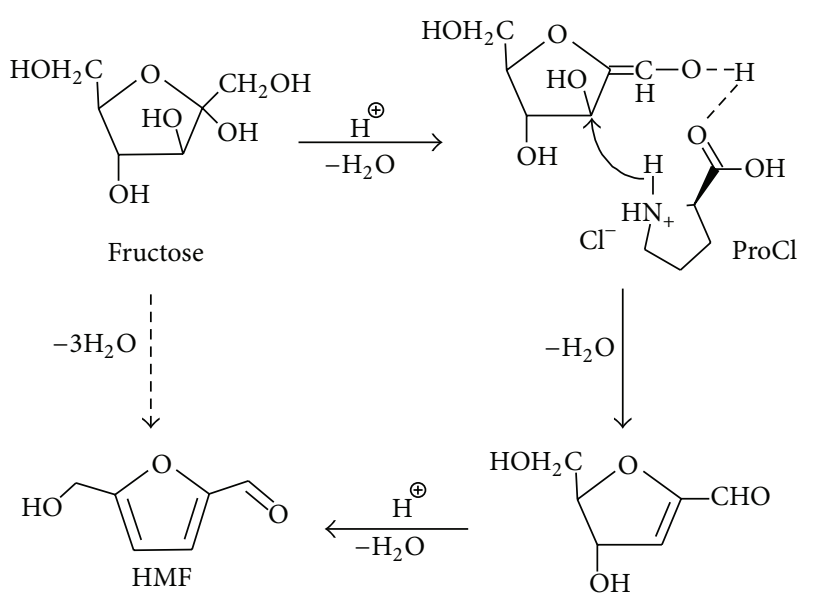

FIGURE 9: Proposed mechanism for catalytic dehydration of fructose to HMF with ProCl. in fructose dehydration might be ascribed to the presence of proton and $-\mathrm{COOH}$ that can promote the interaction of fructose and the IL via $\mathrm{O} \cdots \mathrm{H} \cdots \mathrm{O}$ hydrogen bonding in the rate-determining step (Figure 9). In the whole catalytic process, three water molecules were successively lost with the assistance of $\mathrm{H}^{+}$to give the final product HMF [60].

\section{Conclusion}

ProCl synthesized from a simple protonation reaction by mixing $L$-proline with hydrogen chloride in water was demonstrated to be efficient for the dehydration of fructose as well as sucrose to HMF. A maximum HMF yield of $73.6 \%$ could be obtained from fructose under the response surface methodology (RSM) optimized reaction conditions. $-\mathrm{COOH}$ in $\mathrm{ProCl}$ was proposed to promote the interaction of fructose with the IL via $\mathrm{O} \cdots \mathrm{H} \cdots \mathrm{O}$ hydrogen bonding in the rate-determining step, which might facilitate the catalytic dehydration process.

\section{Conflict of Interests}

The authors declare that there is no conflict of interests regarding the publication of this paper.

\section{Acknowledgments}

This work was financially supported by the International Science \& Technology Cooperation Program of China (2010DFB60840), Social Development S\&T Program (no. SZ-[2009] 3011), National Key Technology R\&D Program (2006BAD07A12), and State Scholarship Fund (no. 201306670004).

\section{References}

[1] C. O. Tuck, E. Pérez, I. T. Horváth, R. A. Sheldon, and M. Poliakoff, "Valorization of biomass: deriving more value from waste," Science, vol. 337, pp. 695-699, 2012.

[2] L. E. Manzer, "Recent developments in the conversion of biomass to renewable fuels and chemicals," Topics in Catalysis, vol. 53, no. 15-18, pp. 1193-1196, 2010.

[3] J. van Haveren, E. L. Scott, and J. Sanders, "Bulk chemicals from biomass," Biofuels, Bioproducts and Biorefining, vol. 2, no. 1, pp. 41-57, 2008.

[4] G. W. Huber, S. Iborra, and A. Corma, "Synthesis of transportation fuels from biomass: chemistry, catalysts, and engineering," Chemical Reviews, vol. 106, no. 9, pp. 4044-4098, 2006.

[5] L. Hu, G. Zhao, W. Hao et al., "Catalytic conversion of biomassderived carbohydrates into fuels and chemicals via furanic aldehydes," RSC Advances, vol. 2, pp. 11184-11206, 2012.

[6] F. Jin and H. Enomoto, "Rapid and highly selective conversion of biomass into value-added products in hydrothermal conditions: chemistry of acid/base-catalysed and oxidation reactions," Energy and Environmental Science, vol. 4, no. 2, pp. 382-397, 2011.

[7] X. Tong, Y. Ma, and Y. Li, "Biomass into chemicals: conversion of sugars to furan derivatives by catalytic processes," Applied Catalysis A: General, vol. 385, no. 1-2, pp. 1-13, 2010. 
[8] Z. Hu, B. Liu, Z. Zhang, and L. Chen, "Conversion of carbohydrates into 5-hydroxymethylfurfural catalyzedby acidic ionic liquids in dimethyl sulfoxide," Industrial Crops and Products, vol. 50, pp. 264-269.

[9] B. Liu, Z. Zhang, and K. Huang, "Cellulose sulfuric acid as a bio-supported and recyclable solid acid catalyst for the synthesis of 5-hydroxymethylfurfural and 5-ethoxymethylfurfural from fructose," Cellulose, vol. 20, pp. 2081-2089, 2013.

[10] F. S. Asghari and H. Yoshida, "Kinetics of the decomposition of fructose catalyzed by hydrochloric acid in subcritical water: formation of 5-hydroxymethylfurfural, levulinic, and formic acids," Industrial and Engineering Chemistry Research, vol. 46, no. 23, pp. 7703-7710, 2007.

[11] C. Li, Z. K. Zhao, A. Wang, M. Zheng, and T. Zhang, "Production of 5-hydroxymethylfurfural in ionic liquids under high fructose concentration conditions," Carbohydrate Research, vol. 345, no. 13, pp. 1846-1850, 2010.

[12] H. B. Zhao, J. E. Holladay, H. Brown, and Z. C. Zhang, "Metal chlorides in ionic liquid solvents convert sugars to 5hydroxymethylfurfural," Science, vol. 316, no. 5831, pp. 15971600, 2007.

[13] X. Tong, M. Li, N. Yan, Y. Ma, P. J. Dyson, and Y. Li, "Defunctionalization of fructose and sucrose: iron-catalyzed production of 5-hydroxymethylfurfural from fructose and sucrose," Catalysis Today, vol. 175, no. 1, pp. 524-527, 2011.

[14] Z. Zhang, B. Liu, and Z. K. Zhao, "Conversion of fructose into 5 - $\mathrm{HMF}$ catalyzed by $\mathrm{GeCl}_{4}$ in $\mathrm{DMSO}$ and $[\mathrm{Bmim}] \mathrm{Cl}$ system at room temperature," Carbohydrate Polymers, vol. 88, no. 3, pp. 891-895, 2012.

[15] X. Qi, M. Watanabe, T. M. Aida, and R. L. Smith Jr., "Selective conversion of ${ }_{D}$-fructose to 5-hydroxymethylfurfural by ionexchange resin in acetone/dimethyl sulfoxide solvent mixtures," Industrial and Engineering Chemistry Research, vol. 47, no. 23, pp. 9234-9239, 2008.

[16] X. Guo, Q. Cao, Y. Jiang, J. Guan, X. Wang, and X. Mu, "Selective dehydration of fructose to 5-hydroxymethylfurfural catalyzed by mesoporous SBA-15- $\mathrm{SO}_{3} \mathrm{H}$ in ionic liquid BmimCl," Carbohydrate Research, vol. 351, pp. 35-41, 2012.

[17] V. Heguaburu, J. Franco, L. Reina, C. Tabarez, G. Moyna, and P. Moyna, "Dehydration of carbohydrates to 2-furaldehydes in ionic liquids by catalysis with ion exchange resins," Catalysis Communications, vol. 27, pp. 88-91, 2012.

[18] F. Guo, Z. Fang, and T.-J. Zhou, "Conversion of fructose and glucose into 5-hydroxymethylfurfural with lignin-derived carbonaceous catalyst under microwave irradiation in dimethyl sulfoxide-ionic liquid mixtures," Bioresource Technology, vol. 112, pp. 313-318, 2012.

[19] H. Li, Q. Zhang, X. Liu et al., "InCl3-ionic liquid catalytic system for efficient and selective conversion of cellulose into 5hydroxymethylfurfural," RSC Advances, vol. 3, pp. 3648-3654, 2013.

[20] Y. Y. Lee and K. C. W. Wu, "Conversion and kinetics study of fructose-to-5-hydroxymethylfurfural (HMF) using sulfonic and ionic liquid groups bifunctionalized mesoporous silica nanoparticles as recyclable solid catalysts in DMSO systems," Physical Chemistry Chemical Physics, vol. 14, pp. 13914-13917, 2012.

[21] H. Li, Q. Zhang, X. Liu et al., "Immobilizing $\mathrm{Cr}^{3+}$ with $\mathrm{SO}_{3} \mathrm{H}-$ functionalized solid polymeric ionic liquids as efficient and reusable catalysts for selective transformation of carbohydrates into 5-hydroxymethylfurfural," Bioresource Technology, vol. 144, pp. 21-27, 2013.
[22] Y. Zhang, V. Degirmenci, C. Li, and E. J. M. Hensen, "Phosphotungstic acid encapsulated in metal-organic framework as catalysts for carbohydrate dehydration to 5-hydroxymethylfurfural," ChemSusChem, vol. 4, no. 1, pp. 59-64, 2011.

[23] X. Qi, M. Watanabe, T. M. Aida, and R. L. Smith Jr., "Sulfated zirconia as a solid acid catalyst for the dehydration of fructose to 5-hydroxymethylfurfural," Catalysis Communications, vol.10, no. 13, pp. 1771-1775, 2009.

[24] Q. Zhao, L. Wang, S. Zhao, X. Wang, and S. Wang, "High selective production of 5-hydroymethylfurfural from fructose by a solid heteropolyacid catalyst," Fuel, vol. 90, no. 6, pp. 22892293, 2011.

[25] C. Lansalot-Matras and C. Moreau, "Dehydration of fructose into 5-hydroxymethylfurfural in the presence of ionic liquids," Catalysis Communications, vol. 4, no. 10, pp. 517-520, 2003.

[26] Y. Li, H. Liu, C. Song et al., "The dehydration of fructose to 5-hydroxymethylfurfural efficiently catalyzed by acidic ionexchange resin in ionic liquid," Bioresource Technology, vol. 133, pp. 347-353, 2013.

[27] G. Yong, Y. Zhang, and J. Y. Ying, "Efficient catalytic system for the selective production of 5-hydroxymethylfurfural from glucose and fructose," Angewandte Chemie, vol. 47, no. 48, pp. 9345-9348, 2008.

[28] Q. Cao, X. Guo, S. Yao et al., "Conversion of hexose into 5hydroxymethylfurfural in imidazolium ionic liquids with and without a catalyst," Carbohydrate Research, vol. 346, no. 7, pp. 956-959, 2011.

[29] L. Hu, Y. Sun, and L. Lin, "Efficient conversion of glucose into 5-hydroxymethylfurfural by chromium(III) chloride in inexpensive ionic liquid," Industrial and Engineering Chemistry Research, vol. 51, no. 3, pp. 1099-1104, 2012.

[30] X. Zhou, Z. Zhang, B. Liu, Z. Xu, and K. Deng, "Microwaveassisted rapid conversion of carbohydrates into 5hydroxymethylfurfural by $\mathrm{ScCl}_{3}$ in ionic liquids," Carbohydrate Research, vol. 375, pp. 68-72, 2013.

[31] Z. Zhang, B. Liu, and Z. K. Zhao, "Catalytic conversion of carbohydrates into 5-hydroxymethylfurfural by Hafnium(IV) chloride in ionic liquids," Starch/Stärke, vol. 64, pp. 770-775, 2012.

[32] N. Mittal, G. M. Nisola, and W.-J. Chung, "Facile catalytic dehydration of fructose to 5-hydroxymethylfurfural by Niobium pentachloride," Tetrahedron Letters, vol. 53, pp. 3149-3155, 2012.

[33] T. Okano, K. Qiao, Q. Bao, D. Tomida, H. Hagiwara, and C. Yokoyama, "Dehydration of fructose to 5hydroxymethylfurfural (HMF) in an aqueous acetonitrile biphasic system in the presence of acidic ionic liquids," Applied Catalysis A: General, vol. 451, pp. 1-5, 2013.

[34] Q. Bao, K. Qiao, D. Tomida, and C. Yokoyama, "Preparation of 5-hydroymethylfurfural by dehydration of fructose in the presence of acidic ionic liquid," Catalysis Communications, vol. 9, no. 6, pp. 1383-1388, 2008.

[35] S. E. Sim, S. Kwon, and S. Koo, "Bis-sulfonic acid ionic liquids for the conversion of fructose to 5-hydroxymethyl-2-furfural," Molecules, vol. 17, pp. 12804-12811, 2012.

[36] Y. Qu, C. Huang, Y. Song, J. Zhang, and B. Chen, "Efficient dehydration of glucose to 5-hydroxymethylfurfural catalyzed by the ionic liquid, 1-hydroxyethyl-3-methylimidazolium tetrafluoroborate," Bioresource Technology, vol. 121, pp. 462-466, 2012.

[37] S. Hu, Z. Zhang, Y. Zhou et al., "Conversion of fructose to 5-hydroxymethylfurfural using ionic liquids prepared from 
renewable materials," Green Chemistry, vol. 10, no. 12, pp. 12801283, 2008.

[38] Y. Qu, Y. Song, C. Huang, J. Zhang, and B. Chen, "Alkaline ionic liquids as catalysts: a novel and green process for the dehydration of carbohydrates to give 5-hydroxymethylfurfural," Industrial \& Engineering Chemistry Research, vol. 51, pp. 1300813013, 2012.

[39] C. Moreau, A. Finiels, and L. Vanoye, "Dehydration of fructose and sucrose into 5-hydroxymethylfurfural in the presence of 1$H$-3-methyl imidazolium chloride acting both as solvent and catalyst," Journal of Molecular Catalysis A: Chemical, vol. 253, no. 1-2, pp. 165-169, 2006.

[40] A. H. Jadhav, H. Kim, and I. T. Hwang, "Efficient selective dehydration of fructose and sucrose into 5-hydroxymethylfurfural (HMF) using dicationic room temperature ionic liquids as a catalyst," Catalysis Communications, vol. 21, pp. 96-103, 2012.

[41] H. Ma, B. Zhou, Y. Li, and D. S. Argyropoulos, "Conversion of fructose to 5-hydroxymethylfurfural with a functionalized ionic liquid," BioResources, vol. 7, no. 1, pp. 533-544, 2012.

[42] M. Markiewicz, M. Piszora, N. Caicedo, C. Jungnickel, and S. Stolte, "Toxicity of ionic liquid cations and anions towards activated sewage sludge organisms from different sources: consequences for biodegradation testing and wastewater treatment plant operation," Water Research, vol. 47, pp. 2921-2928, 2013.

[43] K. de Oliveira Vigier, A. Benguerba, J. Barrault, and F. Jérôme, "Conversion of fructose and inulin to 5-hydroxymethylfurfural in sustainable betaine hydrochloride-based media," Green Chemistry, vol. 14, no. 2, pp. 285-289, 2012.

[44] G.-H. Tao, L. He, N. Sun, and Y. Kou, "New generation ionic liquids: cations derived from amino acids," Chemical Communications, no. 28, pp. 3562-3564, 2005.

[45] N. Kumaragurubaran, K. Juhl, W. Zhuang, A. Bøgevig, and K. A. Jørgensen, "Direct $L$-proline-catalyzed asymmetric $\alpha$ amination of ketones," Journal of the American Chemical Society, vol. 124, pp. 6254-6255, 2002.

[46] T.-P. Loh, L.-C. Feng, H.-Y. Yang, and J.-Y. Yang, " $L$-proline in an ionic liquid as an efficient and reusable catalyst for direct asymmetric aldol reactions," Tetrahedron Letters, vol. 43, no. 48, pp. 8741-8743, 2002.

[47] H. R. Shaterian and M. Aghakhanizadeh, "Mild preparation of chromeno[2,3-d]pyrimidines catalyzed by Brønsted acidic ionic liquids under solvent-free and ambient conditions," Research on Chemical Intermediates, vol. 39, pp. 3877-3885, 2013.

[48] S. Rostamizadeha, M. Nojavana, R. Aryanb, E. Isapoora, and M. Azad, "Amino acid-based ionic liquid immobilized on $\alpha$ $\mathrm{Fe}_{2} \mathrm{O}_{3}$-MCM-41: an efficient magnetic nanocatalyst and recyclable reaction media for the synthesis of quinazolin-4(3H)one derivatives," Journal of Molecular Catalysis A: Chemical, vol. 374-375, pp. 102-110, 2013.

[49] G.-H. Tao, L. He, W.-S. Liu et al., "Preparation, characterization and application of amino acid-based green ionic liquids," Green Chemistry, vol. 8, no. 7, pp. 639-646, 2006.

[50] L. Dong, L. He, G.-H. Tao, and C. Hu, "High yield of ethyl valerate from the esterification of renewable valeric acid catalyzed by amino acid ionic liquids," RSC Advances, vol. 3, pp. 4806-4813, 2013.

[51] H. R. Safaei, M. Shekouhy, V. Shafiee, and M. Davoodi, “Glycerol based ionic liquid with a boron core: a new highly efficient and reusable promoting medium for the synthesis of quinazolinones," Journal of Molecular Liquids, vol. 180, pp. 139-144, 2013.
[52] X. Qi, M. Watanabe, T. M. Aida, and R. L. Smith Jr., "Efficient process for conversion of fructose to 5-hydroxymethylfurfural with ionic liquids," Green Chemistry, vol. 11, no. 9, pp. 1327-1331, 2009.

[53] T. Ståhlberg, S. Rodriguez-Rodriguez, P. Fristrup, and A. Riisager, "Metal-free dehydration of glucose to 5(Hydroxymethyl)furfural in ionic liquids with boric acid as a promoter," Chemistry, vol. 17, no. 5, pp. 1456-1464, 2011.

[54] F. Tao, H. Song, and L. Chou, "Dehydration of fructose into 5hydroxymethylfurfural in acidic ionic liquids," RSC Advances, vol. 1, no. 4, pp. 672-676, 2011.

[55] T. S. Hansen, J. Mielby, and A. Riisager, "Synergy of boric acid and added salts in the catalytic dehydration of hexoses to 5hydroxymethylfurfural in water," Green Chemistry, vol. 13, no. 1, pp. 109-114, 2011.

[56] G. Tian, X. Tong, Y. Wang, Y. Yan, and S. Xue, "Highly efficient and $\mathrm{N}$-bromosuccinimide-mediated conversion of carbohydrates to 5-hydroxymethylfurfural under mild conditions," Research on Chemical Intermediates, vol. 39, pp. 3255-3263, 2013.

[57] J. B. Binder and R. T. Raines, "Simple chemical transformation of lignocellulosic biomass into furans for fuels and chemicals," Journal of the American Chemical Society, vol. 131, no. 5, pp. 1979-1985, 2009.

[58] C. Baroi and A. K. Dalai, "Simultaneous esterification, transesterification and chlorophyll removal from green seed canola oil using solid acid catalysts," Catalysis Today, vol. 207, pp. 74-85, 2013.

[59] C. Wang, L. Fu, X. Tong, Q. Yang, and W. Zhang, "Efficient and selective conversion of sucrose to 5-hydroxymethylfurfural promoted by ammonium halides under mild conditions," Carbohydrate Research, vol. 347, no. 1, pp. 182-185, 2012.

[60] X. Tong and Y. Li, "Efficient and selective dehydration of fructose to 5-hydroxymethylfurfural catalyzed by brønstedacidic ionic liquids," ChemSusChem, vol. 3, no. 3, pp. 350-355, 2010. 

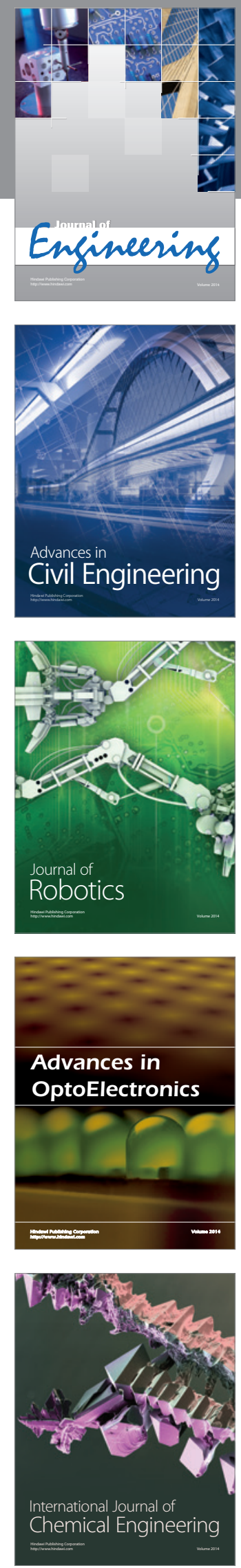

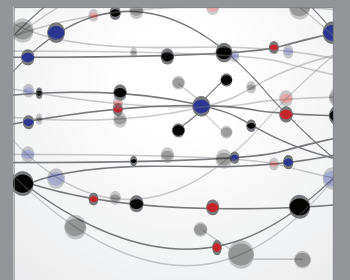

The Scientific World Journal
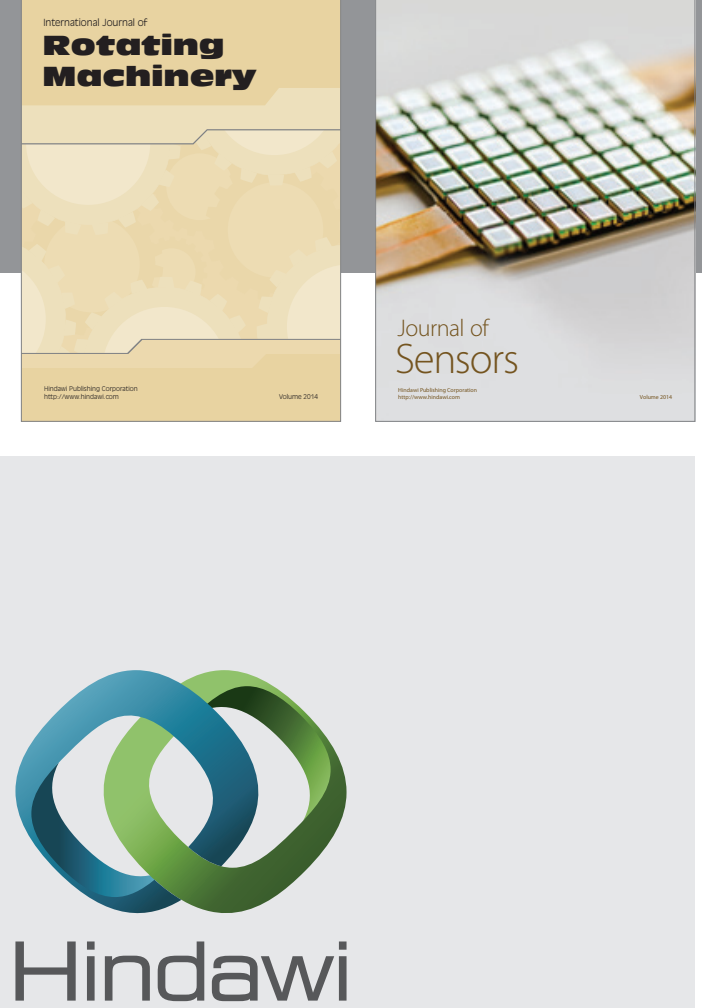

Submit your manuscripts at http://www.hindawi.com
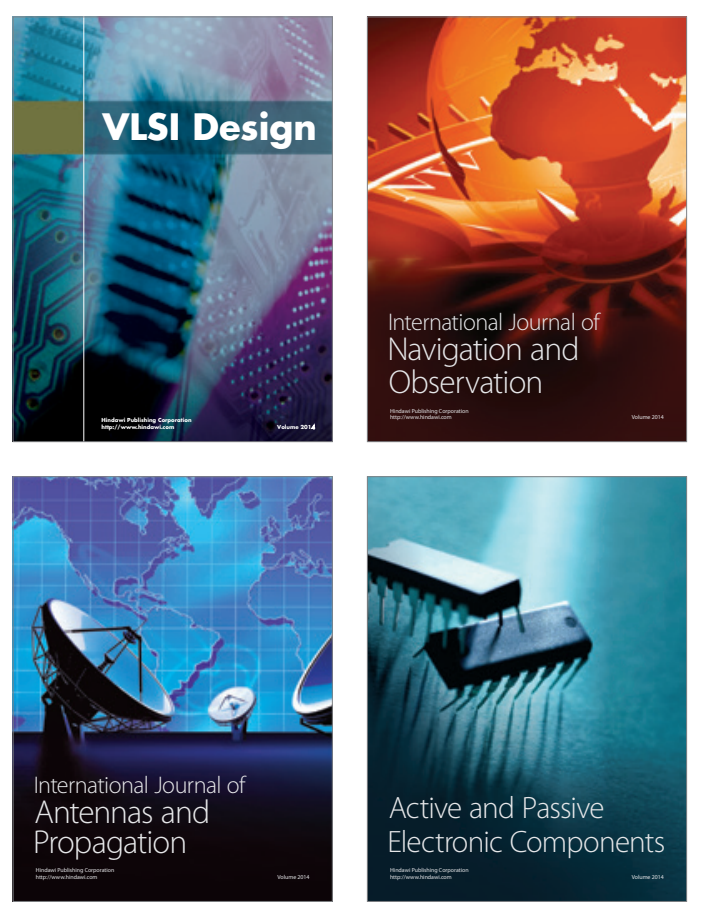
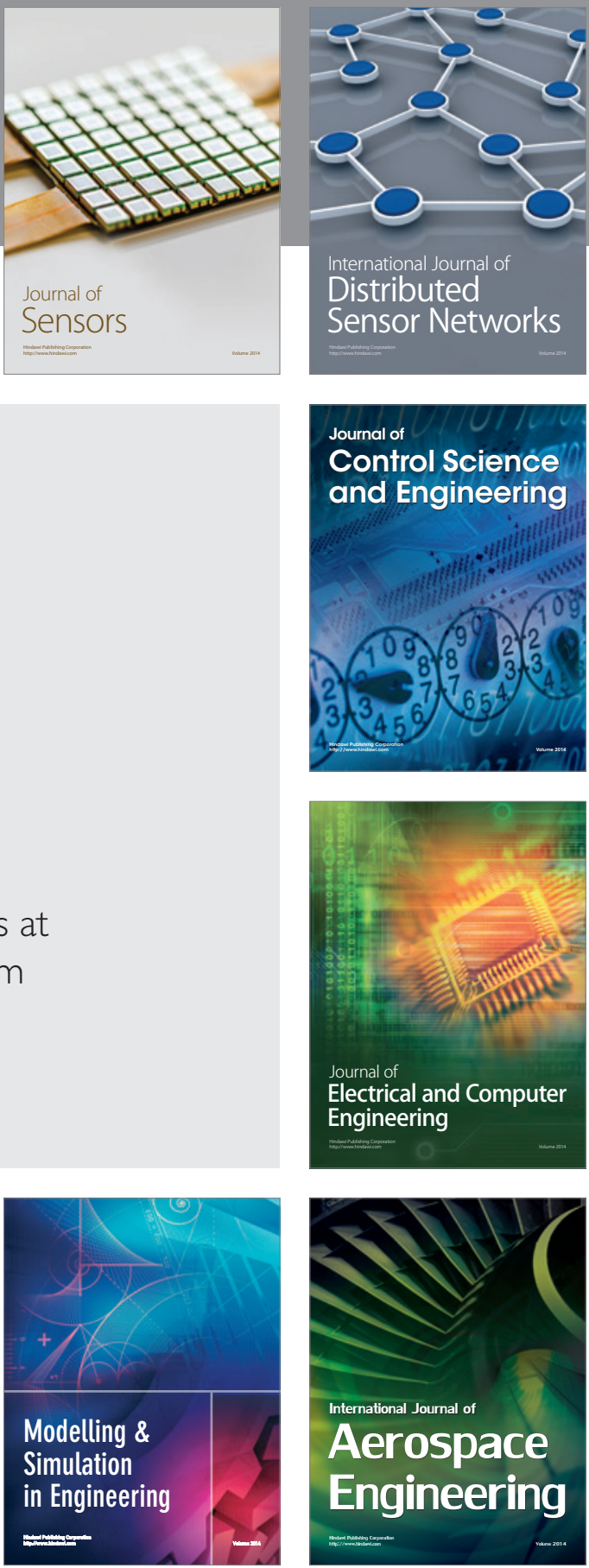

Journal of

Control Science

and Engineering
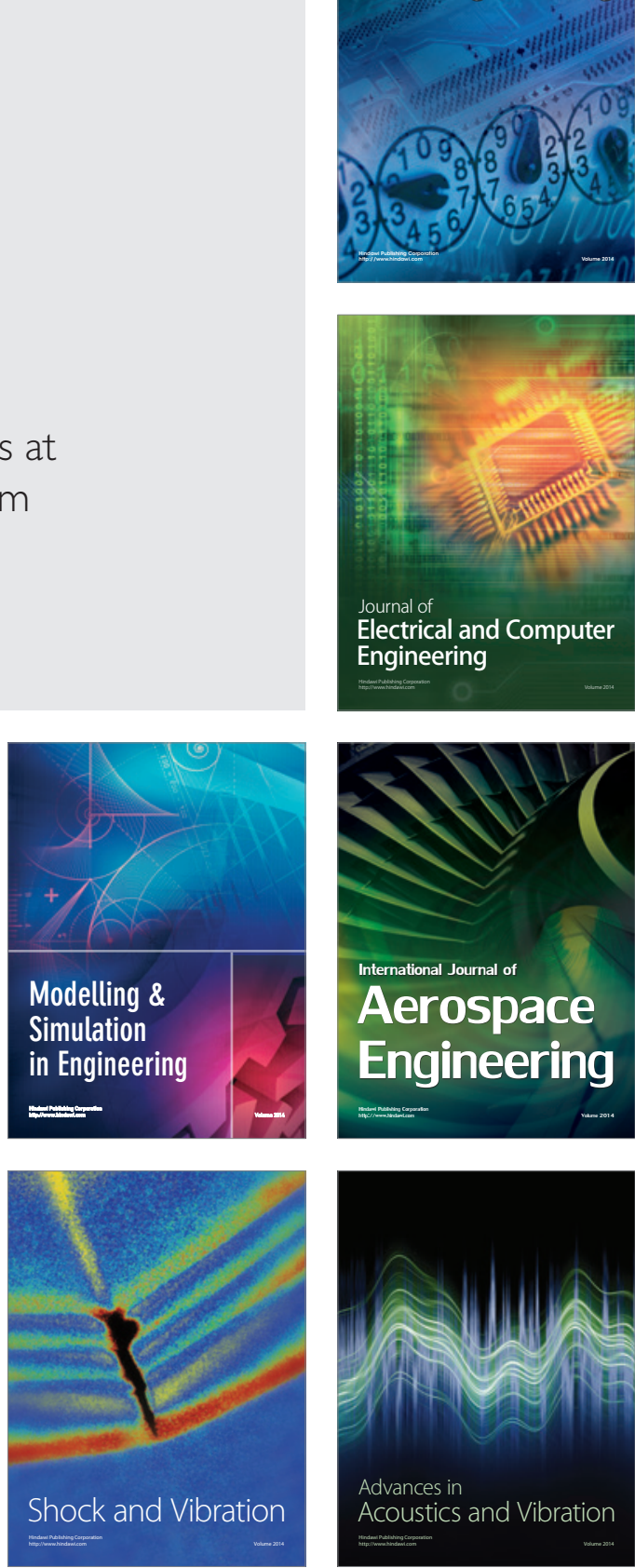